\title{
Recent highlights from Cluster, the first 3-D magnetospheric mission
}

\author{
C. P. Escoubet ${ }^{1}$, A. Masson ${ }^{2}$, H. Laakso ${ }^{1}$, and M. L. Goldstein ${ }^{3}$ \\ ${ }^{1}$ ESA/ESTEC, Noordwijk, the Netherlands \\ ${ }^{2}$ ESA/ESAC, Madrid, Spain \\ ${ }^{3}$ NASA/GSFC, Greenbelt, MD, USA \\ Correspondence to: C. P. Escoubet (philippe.escoubet@esa.int)
}

Received: 20 May 2015 - Revised: 2 September 2015 - Accepted: 4 September 2015 - Published: 2 October 2015

\begin{abstract}
The Cluster mission has been operated successfully for 14 years. During this time period, the evolution of the orbit has enabled Cluster to sample many more magnetospheric regions than was initially anticipated. So far, the separation of the Cluster spacecraft has been changed more than 30 times and has ranged from a few kilometres up to $36000 \mathrm{~km}$. These orbital changes have enabled the science team to address a wide variety of scientific objectives in key regions of Earth's geospace environment: the solar wind and bow shock, the magnetopause, polar cusps, magnetotail, plasmasphere and the auroral acceleration region. Recent results have shed new light on solar wind turbulence. They showed that the magnetosheath can be asymmetric under low Mach number and that it can contain density enhancement that may affect the magnetosphere. The magnetopause was found to be thinner and to have a higher current density on the duskside than on the dawnside. New methods have been used to obtain characteristic of the magnetotail current sheet and high-temporal-resolution measurements of electron pitch angle within flux transfer events (FTEs). Plasmaspheric wind has been discovered, and the refilling of the plasmasphere was observed for the first time over a very wide range of $L$ shells. New models of global electric and magnetic fields of the magnetosphere have been obtained where Cluster, due to its polar orbit, has been essential. Finally, magnetic reconnection was viewed for the first time with high-resolution wave and electron measurements and acceleration of plasma was observed during times of varying rate of magnetic reconnection. The analysis of Cluster data was facilitated by the creation of the Cluster Science Data System (CSDS) and the Cluster Science Archive (CSA). Those systems were implemented to provide, for the first time for a plasma physics mission, a long-term public archive of all calibrated highresolution data from all instruments.
\end{abstract}

Keywords. Magnetospheric physics (magnetopause cusp and boundary layers; plasmasphere; plasma waves and instabilities)

\section{Introduction}

The Cluster mission has become one of the most successful plasma physics mission ever. Its success has resulted from the ability to measure, for the first time, space plasma parameters in three dimensions. From these measurements, it became possible to derive gradients, curls and the divergence of plasma parameters to directly obtain the electric currents, flow vorticity and electric fields that are fundamental to a general understanding of plasma phenomena in space. This capability resulted in the publication of more than 2000 papers in leading magnetospheric journals, including Annales Geophysicae, Journal of Geophysical Research and Geophysical Research Letters. A large number of papers have also been published in wider audience journals (e.g. Nature, Nature Physics and Science) and in plasma physics and astrophysical journals (e.g. Physical Review Letters, Physics of Plasmas, Astrophysical Journal Letters and Journal of Plasma Physics).

In 2005, Paschmann et al. (2015) wrote a book under the auspices of the International Space Science Institute, in which the authors reviewed all results obtained by Cluster investigations of the outer boundaries of Earth's magnetosphere during the first 4 years of the mission. Ten chapters, classified into three parts, were written by various groups of scientists. The first part covered the solar wind, foreshock and magnetosheath; the second part concentrated on the bow shock; and the third part addressed the magnetopause and cusp. Following a workshop at the Belgian Institute for Space 
Aeronomy, Darrouzet et al. (2009) reviewed the latest results obtained with the NASA IMAGE and the ESA Cluster missions on the plasmasphere. These two highly complementary missions, with the global and dynamic views obtained by IMAGE and the simultaneous in situ measurements from Cluster, made this book an essential textbook on the plasmasphere. Escoubet et al. (2013a) presented results obtained from Cluster during the first 12 years of operations, with highlights from the main regions of the Earth's magnetic environment. In particular, that review addressed bow shock motion and electron structures, the wavy nature of the magnetopause, roll-up vortices, large-scale waves in the plasma sheet, plasmasphere density gradients, auroral acceleration dynamics, and the impact of coronal mass ejection on the exterior cusp.

In this paper we concentrate on recent highlights obtained in the last few years. In the first part, we will briefly present the status of the mission and summarise future operations. The second and main part is dedicated to recent science highlights in various regions of the magnetosphere, particularly the following:

- solar wind turbulence,

- magnetopause asymmetries and magnetosheath density enhancements,

- dipolarisation current systems,

- new methods to obtain magnetotail current sheet parameters,

- reconnection variability and its associated highfrequency waves,

- FTEs seen in extremely high detail,

- plasmaspheric wind and refilling of the plasmasphere,

- plasmasphere relation with radiation belts,

- new versions of global electric and magnetic magnetospheric model,

- asymmetries in the magnetosheath and magnetopause elongation under low Mach number solar wind.

In the last part of this paper we will address the second Guest Investigator Programme as part of which observations will take place throughout 2015 and 2016 and the Cluster Science Archive, which is designed to give public and easy access to all high-resolution Cluster data.

\section{Cluster mission}

\subsection{Mission selection and launch}

Cluster was selected, together with the SOlar Heliospheric Observatory (SOHO), as part of the Solar Terrestrial Science Programme, the first cornerstone of the European Space
Agency (ESA) Horizon 2000 programme. The selection process took 4 years since both Cluster and SOHO were in competition and ESA funding was only available for 1 year. Substantial descoping took place during Phase A, where the payloads of both Cluster and SOHO were reduced. Furthermore, a large collaboration was opened with NASA and a memorandum of understanding was agreed to whereby NASA provided the launch and part of the payload and conducted the operations for SOHO. For Cluster, NASA provided instruments and the Deep Space Network for data acquisition of the wideband instrument. The ESA Science Programme Committee (SPC) approved Cluster and SOHO in 1986 and, following an announcement of opportunity, the 11 Cluster instruments were selected in 1988. After the launch failure of the first Ariane 5 on 4 June 1996, the Cluster community undertook a long effort to convince ESA and National Agencies that Cluster was the next big step required to advance space physics. On 3 April 1997, the SPC approved the Cluster II mission to be launched in 2000 on two Soyuz rockets (Credland and Schmidt, 1997). In a little more than 3 years, the fastest implementation time for an ESA space mission, the four Cluster spacecraft were rebuilt, tested and successfully launched on 16 July and 9 August 2000 (Escoubet et al., 2001).

\subsection{Payload}

The Cluster payload (Table 1) is identical on each spacecraft. It measures DC electric and magnetic fields (the EFW, EDI and FGM instruments), electrostatic and electromagnetic waves (DWP, STAFF, WHISPER and WBD), and low- and high-energy ions and electrons (CIS, PEACE and RAPID). In addition, to make the best ion and electron measurements, an indium ion emitter (ASPOC) was used to maintain the spacecraft potential at low voltage (about $7 \mathrm{~V}$ ) with respect to the plasma. Since the first proposal by Haerendel et al. (1982) to the European Space Agency (ESA), 33 years have passed and many of the original principal investigators (PI) involved at the beginning have retired or, sadly, passed away (a list of all past and present Cluster PIs is shown in Table 1). The operations of all instruments have, however, continued without interruption, thanks to the very good knowledge transmission within the experimental teams, ESA and industry.

\subsection{Cluster constellations and orbit: past, present and future}

Cluster is the first 3-D constellation of four scientific spacecraft. Recently, a second four-spacecraft constellation, the Magnetospheric Multiscale (MMS) mission, was launched by NASA. A four-spacecraft constellation is unique in its ability to obtain a three-dimensional picture of plasma structures and thus separate spatial and temporal features. Four spacecraft also allow one to derive physical quantities never measured before, including plasma currents using the curl 
Table 1. The 11 instruments on each of the four Cluster spacecraft. History of PIs is also given.

\begin{tabular}{lrr}
\hline $\begin{array}{l}\text { Instrument/principal investigator } \\
\text { (current and previous) }\end{array}$ & $\begin{array}{r}\text { Mass } \\
(\mathrm{kg})\end{array}$ & $\begin{array}{r}\text { Power } \\
(\mathrm{W})\end{array}$ \\
\hline ASPOC (spacecraft potential control) & 1.9 & 2.7 \\
K. Torkar (IRF, AT) 2001- & & \\
W. Riedler (IRF, AT) 1988-2001 & & \\
\hline
\end{tabular}

CIS (ion composition $0<\boldsymbol{E}<40 \mathrm{keV}$ )

$10.8 \quad 10.6$

I. Dandouras (IRAP/CNRS, FR) 2007-

H. Rème (IRAP/CNRS, FR) 1988-2007

\begin{tabular}{lll}
\hline EDI (plasma drift velocity) & 10.5 & 9.1 \\
R. Torbert (UNH, US) 2006- & & \\
G. Paschmann (MPE, DE) 1988-2006 & & \\
\hline FGM (magnetometer) & 2.6 & 2.2 \\
C. Carr (IC, UK) 2012- & & \\
E. Lucek (IC, UK) 2005-2012 \\
A. Balogh (IC, UK) 1988-2005
\end{tabular}

PEACE (electrons, $0<\boldsymbol{E}<30 \mathrm{keV}$ ) 4.2

A. Fazakerley (MSSL, UK) 1997-

A. Johnstone (MSSL, UK) 1988-1997 †

RAPID (high-energy electrons and ions)
P. Daly (Göttingen U., DE) 1999-
B. Wilken (MPAe, DE) 1988-1999 †

\begin{tabular}{lll}
\hline DWP* (wave processor) & $2.9^{* *}$ & $4^{* *}$ \\
M. Balikhin (Sheffield, UK) 2011- & & \\
H. Alleyne (Sheffield, UK) 1996-2011 & & \\
L. Woolliscroft (Sheffield, UK) 1988-1996 † & & \\
\hline EFW* (electric field and waves) & 16.2 & 3.7 \\
M. André (IRFU, SE) 2000- & & \\
G. Gustafsson (IRFU, SE) 1988-2000 & &
\end{tabular}

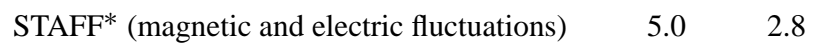

P. Canu (LPP, FR) 2010

N. Cornilleau-Werhlin (LPP, FR) 1988-2010

\begin{tabular}{llc}
\hline WBD* (electric field and wave forms) & 1.8 & 1.7 \\
J. Pickett (Iowa, US) 2006- & & \\
D. Gurnett (Iowa, US) 1988-2006 & & \\
\hline WHISPER* (electron density and waves) & 1.8 & 1.8 \\
J.-L. Rauch (LPC2E, FR) 2012- & & \\
J. G. Trotignon (LPC2E, FR) 2007-2012 & & \\
P. Décréau (LPC2E, FR) 1988-2007 & & \\
\hline Total & 65.2 & 47.3
\end{tabular}

* Members of the wave experiment consortium (WEC)

** Including power supply

$\dagger$ Deceased

of the magnetic field and velocity and plasma gradients (e.g. density gradients, the divergence of the electron pressure tensor, the vorticity of the plasma). The spacecraft formation varies in size naturally around the orbit, which enables multipoint measurements in different regions at various scales.
A key driver of the new Cluster science investigations over the various mission extensions has been the orbit evolution, which was caused by Sun-Moon gravitational perturbations. This has drastically altered Cluster's nominal polar orbit over time and facilitated access to regions of near-Earth space that were not originally targeted by Cluster. For example, due to the lowering of perigee, which reached $\sim 250 \mathrm{~km}$ for $\mathrm{C} 2$ in 2011 , lower-altitude phenomena such as the auroral acceleration region became an accessible scientific target.

To summarise the evolution of the various orbital elements, examples of orbits from various years of the mission are plotted in Fig. 1. At the beginning of the mission (20012005) the southern and northern exterior cusp and the nearEarth magnetotail (19 $R_{\mathrm{E}}$ from Earth) were the prime targets. In 2009, the apogee moved to the Southern Hemisphere and the perigee altitude dropped dramatically, allowing, for the first time, visits to the subsolar magnetopause, the magnetotail current disruption region $\left(8-10 R_{\mathrm{E}}\right)$ and the auroral acceleration region. Since 2009 the rotation of the orbit has reversed, and the outbound magnetopause is now located in the Southern Hemisphere and the inbound leg is in the Northern Hemisphere.

In 2013, the perigee altitude was increased again and apogee started returning to the Northern Hemisphere. With the increase of perigee up to 6-7 $R_{\mathrm{E}}$ in 2017-2018, for the first time Cluster will visit the jet braking region on the nightside of the magnetosphere. Because of its highly inclined orbit in future years, Cluster will also cross the polar cusp in azimuthal direction and will be able to determine the extent of the exterior cusp in longitude while investigating its dawndusk asymmetries.

A key feature of the Cluster mission is its ability to modify the inter-spacecraft separation distances to optimise studying the regions or physical processes of greatest interest and significance. The separation distances between the spacecraft achieved so far and planned for the future are shown in Fig. 2. From February 2001 to June 2005, the constellation was such that a perfect tetrahedron was formed twice along the orbit. This allowed, at the expense of a bit more fuel, to have perfect three-dimensional measurements in two separated places, the northern cusp and the southern magnetopause, while still maintaining a very good three-dimensional configuration during a large part of the orbit - through the magnetosheath and the solar wind. Six months later, once the apogee was in the tail, two tetrahedra were formed in the lobes, allowing perfect three-dimensional measurements throughout the entire plasma sheet.

Starting in 2005, after forming a $10000 \mathrm{~km}$ tetrahedron and having used three-quarters of the fuel capacity, a more frugal approach to spacecraft separation was implemented by moving them along their orbit. These phasing manoeuvres are implemented by initiating a drift of a spacecraft and some time later (a few weeks to a few months) stopping that drift once the desired configuration is reached. For example, shifting Cluster 3 by $1 \mathrm{~h}$ along its orbit over a period of 3 weeks 

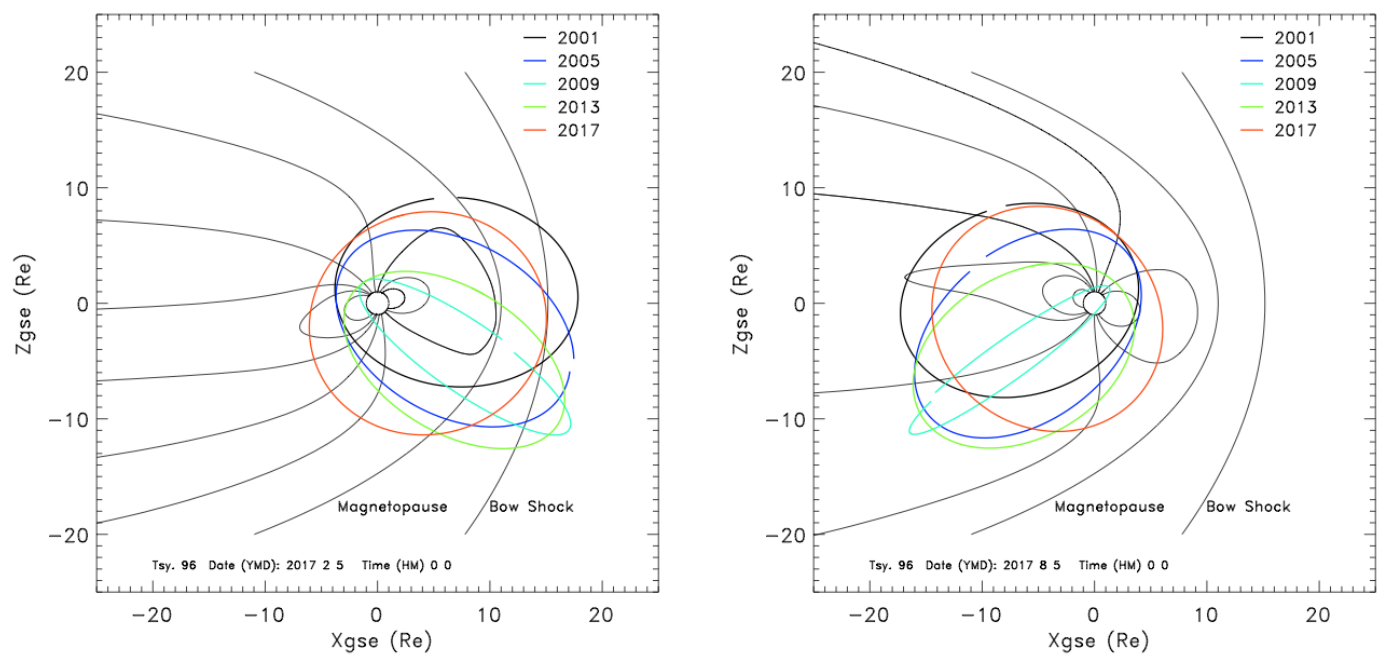

Figure 1. A broad sample of Cluster orbits from 2001 to 2017 in geocentric solar ecliptic (GSE) coordinates. The nominal magnetopause and bow shock positions as well as the magnetic field lines have been derived from the Tsyganenko 1996 model (date indicated at the bottom) and plotted as black lines. The orbit when the apogee is in the solar wind is shown on the left, and that when the apogee is in the magnetotail, 6 months later, is shown on the right. Note that the earlier years (2001-2005) show incomplete orbits since the orbital period (57h) was longer than in later years $(54 \mathrm{~h})$.

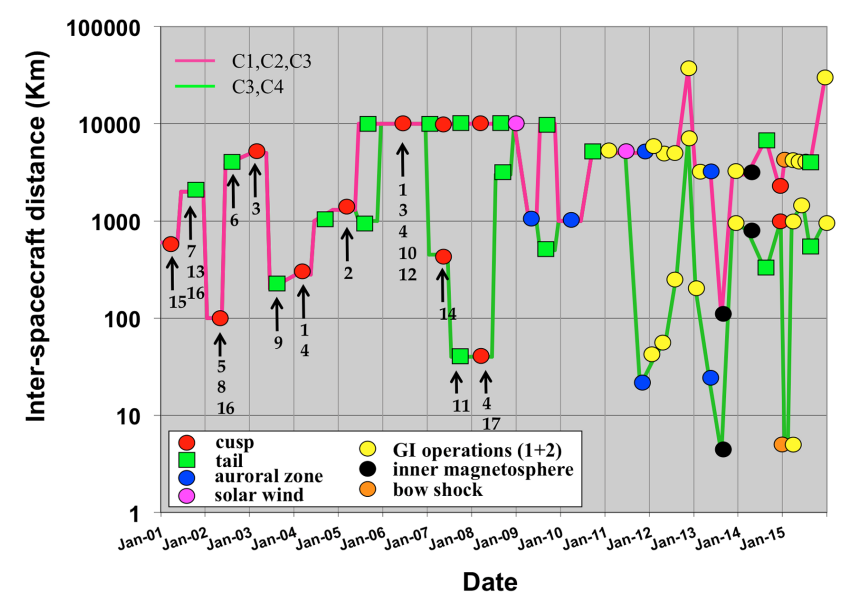

Figure 2. Cluster constellation from the beginning of mission up to now. The distance between the spacecraft is given as a function of time: $\mathrm{C} 1, \mathrm{C} 2$ and $\mathrm{C} 3$ separation distance in magenta and $\mathrm{C} 3$ and $\mathrm{C} 4$ in green. The distance is given at one point along the orbit defined by the symbol and colour in the legend. The arrows and numbers refer to Cluster constellations used in the new scientific highlights presented in this paper.

uses $0.12 \mathrm{~kg}$ of fuel (and the same amount to return it to its original orbit). The same manoeuvre could be implemented in half the time but using twice the amount fuel. Considering that the Cluster orbit ellipse is around $350000 \mathrm{~km}$, an hour phase shift is around $1 R_{\mathrm{E}}$ in distance. This is how Foullon's guest investigator (GI) operations (more than $36000 \mathrm{~km}$ between the spacecraft) have been implemented while using only $0.1-0.6 \mathrm{~kg}$ of fuel per spacecraft (see Sect. 4 for fur- ther details on the GI Programme). The projected fuel consumption for such activities still provides ample opportunities for re-configuration of the spacecraft up to at least the end of 2018. In May 2014, to save even more fuel, the Science Working Team (SWT) agreed to fix the spacecraft attitude in the range $88-92^{\circ}$ solar aspect angle to avoid future 3 -monthly attitude manoeuvres. At this attitude, the stability of the spinning Cluster spacecraft is such that, if fuel is depleted on one spacecraft, it could still continue to operate for many years. Hence, the mission could continue if one spacecraft runs out of fuel by moving the other three spacecraft around it.

The papers summarised in the science highlights section used either long-term statistical analysis covering many years of data or special events. We have marked the separation distances that were used in the special events with an arrow and a number in Fig. 2. We can see that the new results cover a broad range of separation distance from a few tens of kilometres up to $10000 \mathrm{~km}$. The fact that these highlights used only data up to 2009 is due to the selection of papers itself and the topics covered. For instance, many papers have been published based on auroral acceleration and inner magnetosphere campaigns, with data from 2009 to 2014; some of them can be found in Escoubet et al. (2013a) and all of them on the Cluster web page (http://sci.esa.int/cluster/).

\subsection{Synergy with MMS and other magnetospheric missions}

Together with Cluster, the newly launched NASA MMS mission will investigate the magnetic reconnection process in unprecedented detail. We will, for the first time, have two 

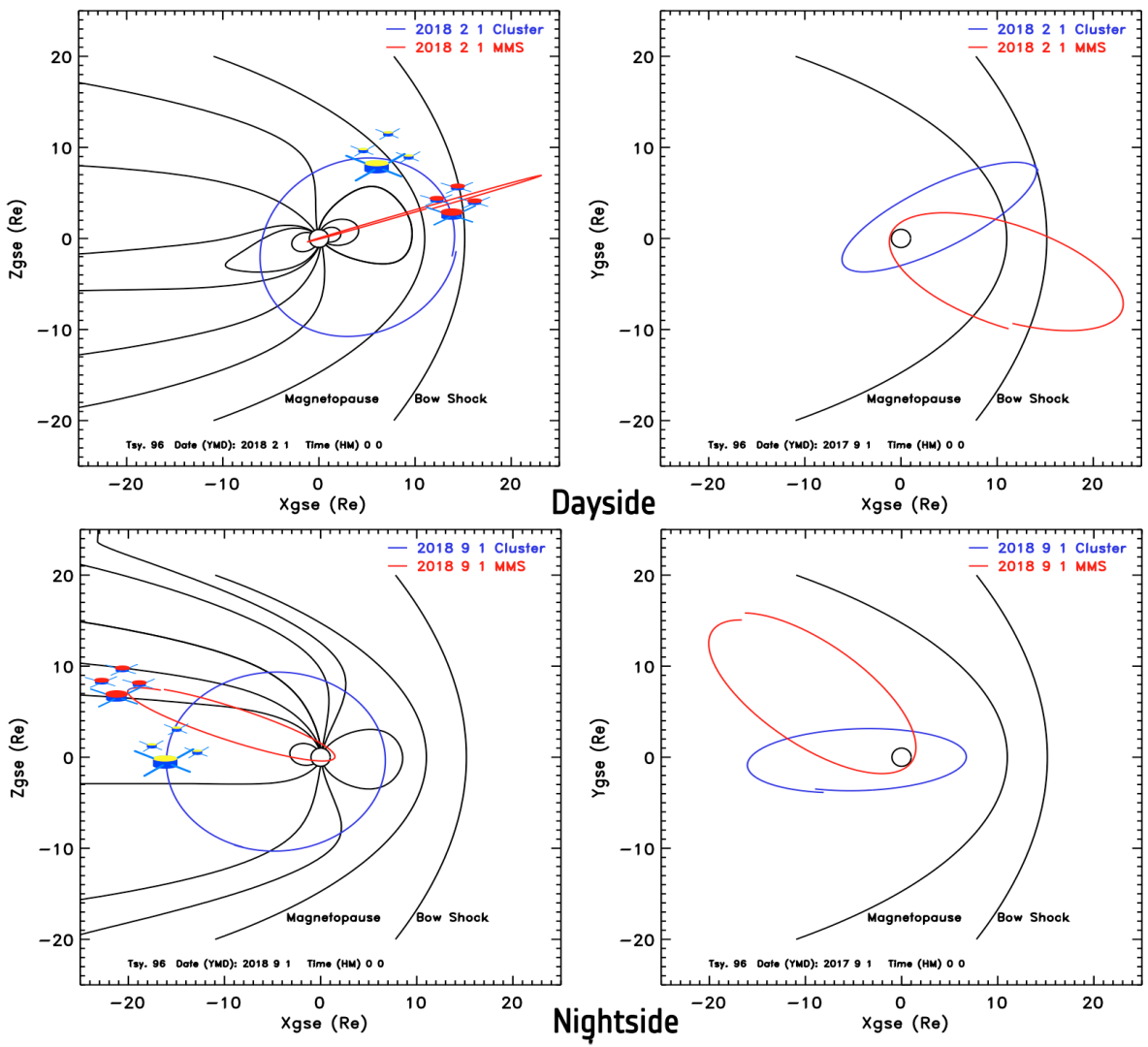

Figure 3. Cluster and MMS orbits on 1 February 2018 in $X Z_{\mathrm{GSE}}$ (top left) and $X Y_{\mathrm{GSE}}$ (top right). Cluster and MMS orbits on 1 September 2018 in $X Z_{\mathrm{GSE}}$ (left) and $X Y_{\mathrm{GSE}}$ (right).

four-spacecraft constellations observing the dayside of the magnetosphere at the same time. We will therefore be able to use two four-point measurements to fully characterise the reconnection process, such as the location of magnetic nulls, the extent of the electron diffusion region, and the electron pressure tensor contribution to the electric field. Figure 3 (top) shows the Cluster (blue) and MMS (red) orbit when their apogees will be in the solar wind. Both spacecraft will be in the same azimuthal sector (separation of line of apsides around $45^{\circ}$ in $X Y_{\mathrm{GSE}}$ ), allowing both missions to be in the solar wind, magnetosheath and magnetopause/cusp at the same time. Cluster will cross the exterior cusp and MMS the magnetopause in the equatorial plane, looking at the effect of subsolar reconnection in the cusp and the extent of the reconnection line in latitude. In addition, with their separation in $X Y_{\mathrm{GSE}}$, the dawn and dusk magnetosheath will be observed at the same time, which will allow the investigation of possible asymmetries. Finally, the quasi-perpendicular and quasiparallel bow shock will also be observed at the same time.

Six months later, the two tetrahedral constellations will be in the magnetotail at the same time (Fig. 3, bottom), with MMS further down the tail than Cluster. The separation of the line of apsides will now be below $40^{\circ}$ in $X Y_{\mathrm{GSE}}$. Both spacecraft constellations would then be in the plasma sheet at around the same time, MMS at about $25 R_{\mathrm{E}}$ and Cluster at around $16 R_{\mathrm{E}}$ downtail. We will therefore be able to study the magnetotail for the first time with two four-spacecraft constellations. To complement these constellations, Geotail will be in the tail at around $30 R_{\mathrm{E}}$ and ARTEMIS (the THEMIS B and $\mathrm{C}$ probes) will be located at around $60 R_{\mathrm{E}}$ down the tail. We will therefore be able to catch reconnection events and study their consequences for the magnetotail, both earthward and tailward. This will enable to investigate the generation of plasmoids, bursty bulk flows, dipolarisation fronts and particle acceleration. THEMIS A, D and E will be located approximately $180^{\circ}$ away from Cluster and MMS apogees and will add a global aspect to the reconnection process from dayside to nightside. Meanwhile, the Van Allen Probes will monitor the ring current and radiation belts and will be in a position to see effects of magnetic reconnection and bursty bulk flows close to the Earth.

\section{Cluster science highlights}

Cluster has observed in 3-D all main regions of the magnetospheric environment, from the dense solar wind, magnetosheath and cusp to the more tenuous magnetotail lobes and plasma sheet. It also went close to the Earth in the plas- 
Table 2. Breakdown of Cluster and Double Star publications in particular journals up to the end of 2014.

\begin{tabular}{lr}
\hline Journals & Number \\
\hline Nature & 19 \\
Astrophysical Journal & 35 \\
Physical Review Letters & 66 \\
Space Science Reviews & 81 \\
Physics of Plasmas & 47 \\
Journal of Geophysical Research & 643 \\
Geophysical Research Letters & 197 \\
Annales Geophysicae & 474 \\
Other & 534 \\
\hline Total & 2096 \\
\hline
\end{tabular}

masphere and radiation belts as well as into the auroral acceleration region and the low-altitude polar cusp. Given the broad range of topics, a large community was involved in these investigations, which resulted in one of the largest refereed publication lists for a space physics mission. Up to the end of 2014, 2096 papers have been published in the refereed literature (Table 2). We will describe here highlights of Cluster results that have been published during the last few years of operations. For previous highlights see Escoubet et al. (2013a).

\subsection{Solar wind turbulence}

One of the long-standing puzzles of solar physics is that the solar wind is hotter than expected as it propagates across the heliosphere. Turbulence is believed to play a role in this heating. A new study of solar wind turbulence investigated the spatial properties of magnetic fluctuations (Perri et al., 2012). The Cluster data (number 1 in Fig. 2), together with numerical simulations, show that the plasma turbulence is virtually two-dimensional and consists of thin current sheets that lie perpendicular to the plane of the average magnetic field of the solar wind. The study made use of the high time resolution of the Spatio-Temporal Analysis Field Fluctuation (STAFF) search coil magnetometer, which is attached at the tip of a $5 \mathrm{~m}$ rigid boom on each of the four Cluster spacecraft. STAFF is capable of detecting rapid variations in magnetic fields, which means that very small spatial structures can be recognised within the plasma. The current sheet analysed had a scale size of $38 \mathrm{~km}$, which falls in between the ion and electron scales.

The energy spectrum of the solar wind turbulence could be modelled by Narita (2014) using a parametric model. This model is based on tools developed for turbulence in fluids and was applied to Cluster data obtained in the solar wind for a separation distance of $1300 \mathrm{~km}$ (number 2 in Fig. 2). Plasma turbulence could then be condensed in four parameters. Although there are limitations in the applicability of the model, it is a very useful method to compare observational and theoretical spectra.

Servidio et al. (2014) investigated the relaxation of turbulence in the solar wind. They used current density and flow vorticity, computed from the four-spacecraft magnetic and electron data at 5000 and $10000 \mathrm{~km}$ inter-spacecraft distances (number 3 in Fig. 2), to show that there exist local patches of equilibrium-like states within the turbulent cascade. Past theoretical works had suggested that these states would appear only after a long time, when the turbulent cascade would have terminated.

Other studies using STAFF search coil data (Alexandrova et al., 2012; Sahraoui et al., 2012) have investigated the approach to the dissipation range of solar wind turbulence and have determined, for the first time, the three-dimensional structure of the magnetic fluctuations.

\subsection{The magnetopause and cusp}

The magnetopause and cusp have been two of the main targets of the Cluster mission since the beginning of the mission, and the orbit was specially designed to cross the highlatitude magnetopause and external cusp. Recently, Haaland and Gjerloev (2013) used a large number of magnetopause crossings on the dawn and dusk flanks of the magnetosphere to identify a dawn-dusk asymmetry of the thickness and current density of the magnetopause: the magnetopause is thinner and shows a higher density current on the duskside. Using SuperMAG, a very large network of ground-based magnetometers, they also observed a stronger ring current on the duskside than on the dawnside at the same time. It is not yet clear whether a link exists between these two currents or if this asymmetry is externally driven by magnetosheath asymmetries (Fig. 5), as reported by Walsh et al. (2012). Further studies will be needed to explain it. Fuselier et al. (2014) investigated magnetic reconnection under northward interplanetary magnetic field (IMF) using crossings of the magnetopause at different latitudes, thanks to the evolution of the Cluster orbit (number 4 in Fig. 2). They showed that most of the time reconnection occurred on both lobes poleward of the cusp (dual lobe) as long as the reconnection times between the two hemispheres are separated by several minutes.

At the magnetopause, magnetic reconnection is usually believed to be the main process responsible for a direct entry of magnetosheath plasma in the magnetosphere. Laboratory experiments have, however, shown that plasma clouds can penetrate into regions of abruptly increased magnetic fields (Brenning et al., 2005) and the impulsive penetration process has recently been investigated again. Karlsson et al. (2012) performed a statistical analysis of density enhancements $(>50 \%)$ in the magnetosheath. Using the four spacecraft they found a scale size between 0.1 and $10 R_{\mathrm{E}}$ in the direction perpendicular to the magnetic field and 3 to 10 times larger in the other directions. They also found that their longest size was usually oriented parallel to the magne- 

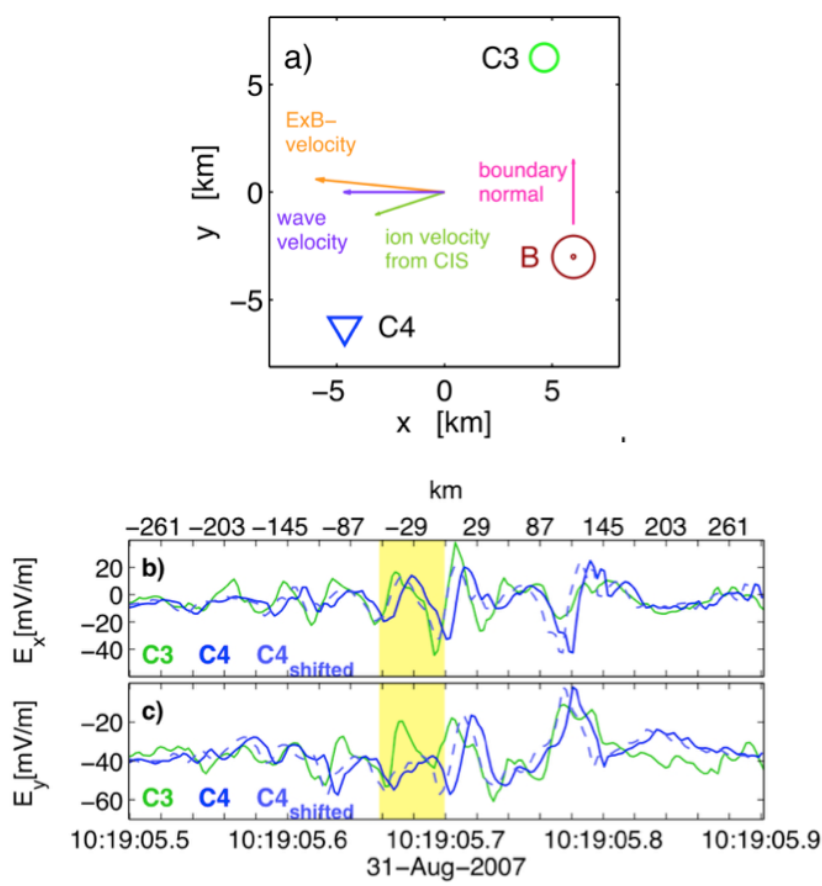

Figure 4. Top: spacecraft configuration and particle flows in the wave velocity and boundary normal coordinate system. Bottom: lower hybrid drift waves detected with two of Cluster's spacecraft separated by $40 \mathrm{~km}$ (adapted from Norgren et al., 2012.)

topause and bow shock. Subsequently, Gunell et al. (2012) showed that plasma could penetrate the magnetopause and its motion could be followed by two spacecraft separated by $100 \mathrm{~km}$ (number 5 in Fig. 2) on closed field lines. Although they stated that reconnection was also most likely happening, the motion of the plasmoid on closed field lines was best explained by impulsive penetration.

Motion of the magnetopause usually induces a motion of the cusp, especially in the high-altitude region where the cusp and magnetopause are directly linked. Escoubet et al. (2013b) showed that a double encounter of the cusp, seen by the first two Cluster spacecraft and not by the last ones, 15 min later (number 6 in Fig. 2), was very likely due to a quick motion of the cusp after the change of IMF- $\boldsymbol{B}_{y}$ and IMF- $\boldsymbol{B}_{z}$. Shi et al. (2014) published a case study where an unusual high flux of electrons was observed by the four Cluster spacecraft within a few tens of minutes (number 7 in Fig. 2). This was explained by the high solar wind dynamic pressure during a southward IMF- $\boldsymbol{B}_{z}$, which allowed the injection of a high-density plasma in the cusp.

\subsection{Plasma sheet dynamics}

Bursty bulk flows (BBFs) are well known to transport energy and plasma toward the Earth during magnetic substorms. Usually magnetohydrodynamics (MHD) flow parameters are used to calculate the energy flux density contained in BBFs.
A new method has been developed by Cao et al. (2013) based on the ion velocity distribution function when the spacecraft were at $100 \mathrm{~km}$ inter-spacecraft distance (number 8 in Fig. 2). This method gives an energy flux density nearly 3 times higher than using MHD parameters (Fig. 6). This result is due to the ion distribution function not being Maxwellian. This more accurate description suggests that BBFs can carry up to one-third of the total energy transferred toward Earth during a substorm; hence, BBFs could represent a significant contributor to the brightening of aurorae.

The braking of bursty bulk flow when approaching the Earth's strongest magnetic field is often associated with magnetic dipolarisation. Yao et al. (2013) investigated the current structures around dipolarisation fronts using high-resolution magnetic field data. They use Cluster data from 2003, when the spacecraft separation $(200 \mathrm{~km})$ (number 9 in Fig. 2) was smaller than the size of the current sheets. They were able sort the dipolarisations into two types (one with a magnetic dip and one without) and characterise the currents associated with them in the dawn-dusk direction.

Kronberg et al. (2012) investigated how the near-Earth hydrogen and oxygen ions $(>10 \mathrm{keV})$ depend on geomagnetic activity and solar wind parameters. They found that $\mathrm{H}+$ ions are only slightly affected by the geomagnetic activity (AE and Dst indices) or the solar wind parameters (dynamic pressure and density). Oxygen ions, on the other hand, vary significantly with geomagnetic activity, with the $10 \mathrm{keV}$ ions more affected than ions with energies greater than $274 \mathrm{keV}$. In addition, the $>274 \mathrm{keV} \mathrm{O}+, \mathrm{H}+$ and $\mathrm{O}+/ \mathrm{H}+$ ions are correlated with the IMF direction. This shows that the acceleration processes in the near-Earth magnetosphere are massdependent.

Using a novel method, Narita et al. (2013) investigated the dynamic of the tail current sheet. Their method is based on eigenvalue and minimum variance analysis applied to Harris current sheet geometry. The advantages of this method are that it only needs four-point magnetic field measurements to deduce the distance and the thickness of the current sheet and that the current sheet parameters are estimated when the spacecraft are outside the current sheet. The inter-spacecraft distance used for this study was $10000 \mathrm{~km}$ (number 10 in Fig. 2). Non-Harris-type current sheets would need to be used to generalise this method.

Cluster is well known to be capable of measuring plasma properties at ion scales. However, during four time periods after 2005, two of the spacecraft were manoeuvred to very small separations of less than $50 \mathrm{~km}$ (Fig. 2), thus probing electron spatial scales directly for the first time. When $\mathrm{C} 3$ and $\mathrm{C} 4$ were at $40 \mathrm{~km}$ from each other in the magnetotail in August 2007 (number 11 in Fig. 2), lower hybrid drift waves, a special type of plasma wave that develops in thin boundaries both in space and in the laboratory, were detected and characterised by Norgren et al. (2012). These waves were detected at a sharp gradient in density and magnetic field. Using the two spacecraft, the propagation direction, phase ve- 

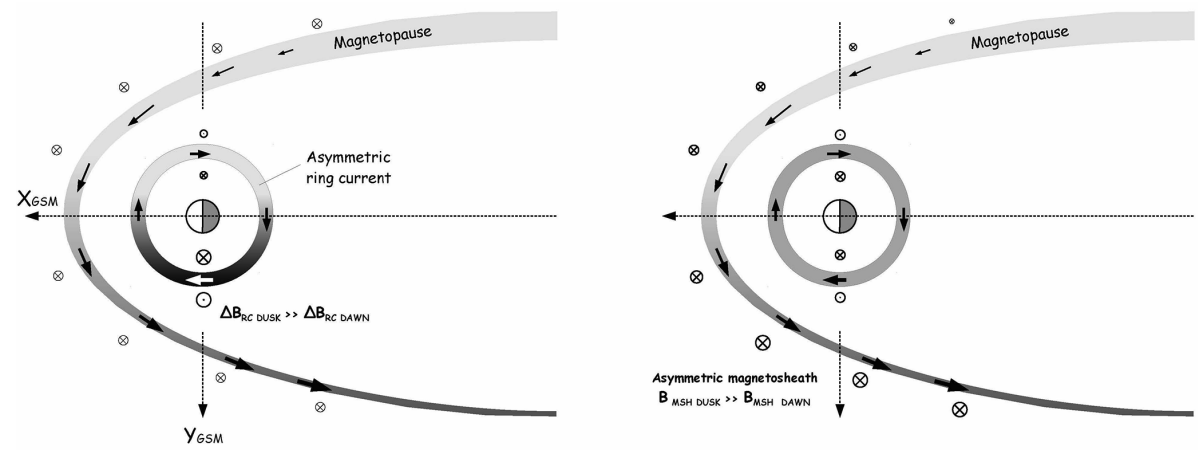

Figure 5. Possible explanations for the asymmetric magnetopause current density: internal, caused by ring current (left), or external, caused by magnetosheath (right) (from Haaland and Gjerloev, 2013).

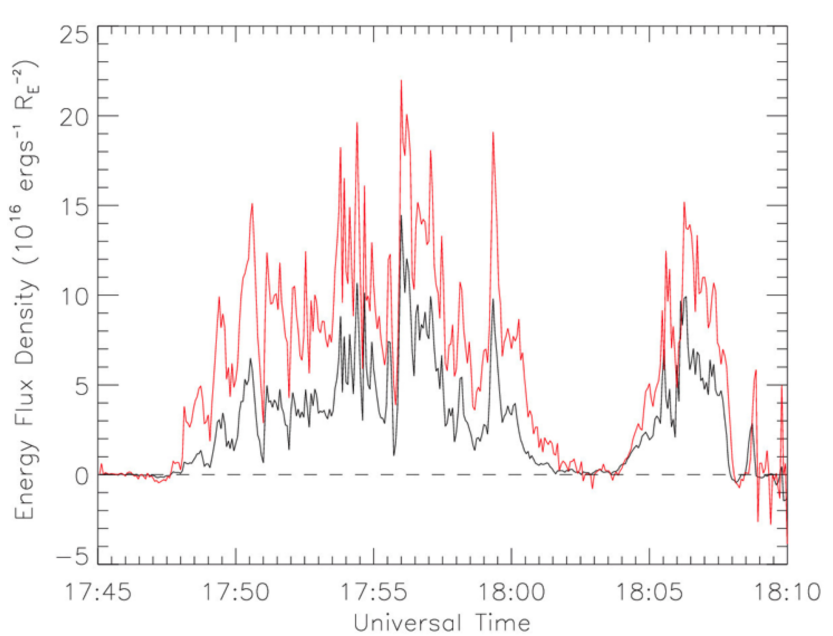

Figure 6. Energy transferred by bursty bulk flows, calculated using two different approaches (from Cao et al., 2013): the red line shows the energy density flux as computed from the data by using the kinetic approach, and the black line shows the same quantity calculated in the magnetohydrodynamics (MHD) approximation. For this magnetic substorm, the value calculated using the kinetic approach is larger than the value derived from the MHD approximation.

locity $\left(1400 \mathrm{~km} \mathrm{~s}^{-1}\right)$ and wavelength $(60 \mathrm{~km})$ were obtained (Fig. 4). These numbers agree well with a theory of the formation of lower hybrid drift waves. These waves should have an effect on electrons, but that effect could not be verified due to the limited time resolution of the electron distribution functions.

\subsection{Reconnection dynamics}

Magnetic reconnection is known to accelerate plasma flowing through the $X$ line. In the Earth's magnetosphere, energetic electrons of a few $100 \mathrm{keV}$ are observed during reconnection and have been attributed to several processes such as $X$ line Joule heating, reconnection electric fields and parallel electric fields. Knowing that energetic electrons are absent in

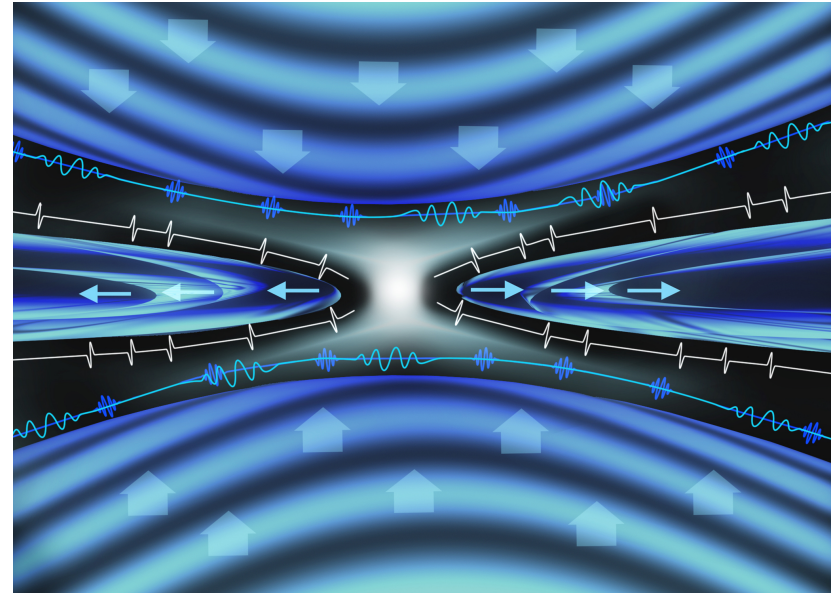

Figure 7. Sketch of waves observed in the separatrix of the reconnection region. The data revealed that both low- and high-frequency waves - known as electron-cyclotron waves (represented in cyan in this illustration) and Langmuir waves (represented in blue) - are present in the vicinity of the inflowing plasma. Single-pulsed waves called electrostatic solitary waves (represented in white) are found closer to the outflowing plasma.

solar wind reconnection events, Fu et al. (2013) investigated why they were present in magnetotail reconnection events using an inter-spacecraft distance of $10000 \mathrm{~km}$ (number 12 in Fig. 2). They showed that the variability of the reconnection process was producing energetic electrons through betatron and Fermi accelerations in the reconnection outflow jet.

The four Cluster spacecraft have been used to make a detailed study of the high-frequency waves near a magnetic reconnection event (Viberg et al., 2013). Special highresolution waveforms were used together with high-timeresolution $(125 \mathrm{~ms})$ energy sweeps of the electron detector when the spacecraft were separated by $2000 \mathrm{~km}$ (number 13 in Fig. 2). Three types of waves were observed within the separatrix regions: Langmuir waves, electron solitary waves and electron cyclotron waves (Fig. 7). Electron cyclotron waves were observed for the first time inside this region. 
The separatrix region is a spatially stratified structure where (i) the outer part is made of Langmuir waves together with electron beams moving away from the $X$ line, and (ii) the inner part is where electron solitary waves are observed together with counter-streaming electron populations. Meanwhile, electron cyclotron waves were observed in different parts of the separatrix region.

At medium scales, around a few Earth radii, a signature of reconnection is a flux transfer event (FTE). Recent observations of Varsani et al. (2014) took advantage of the magnetic field aligned with the spin axis to obtain highresolution (32 $\mathrm{ms}$ ) pitch-angle electron distribution within an FTE. They showed that the FTE contained many individual layers of plasma with a cold population inside the FTE and antiparallel electrons on the edge. Strongly field-aligned ions with speeds approaching the Alfvén speed were observed along with bidirectional electrons near the rearward edge of the FTE. These observations were obtained when Cluster was crossing the magnetopause around the subsolar point in 2007 (see evolution of Cluster orbit in previous section) and a multi-scale spacecraft configuration of $450-10000 \mathrm{~km}$ (number 14 in Fig. 2).

Recently, Roux et al. (2015) analysed in detail two consecutive FTEs when Cluster crossed the magnetopause at high latitudes, when the inter-spacecraft distance was $600 \mathrm{~km}$ in 2001 (number 15 in Fig. 2). They found that the magnetic field lines were closed on the leading edge and opened on the trailing edge, with one footprint connected to the Earth. The comparison of the two FTEs suggested that there exist two states: the first FTE being active with reconnection accelerating ions on the trailing part and the second one being passive, most likely the remnant of an active one. The four spacecraft were used to determine the shape of the FTE with a bump protruding first outward and then inward.

\subsection{Plasmasphere and ring current}

The plasmasphere is the cold torus of particles located around and co-rotating with the Earth. During active times, plumes are formed at the edge of the plasmasphere (plasmapause) on the duskside and are released outwards into the magnetosphere, sometimes all the way to the magnetopause. This mechanism provides a way for plasma to escape from the inner magnetosphere. Such a release can affect the interaction of the solar wind with the magnetosphere by changing reconnection rates and suppressing energy transport. In 1992, Lemaire and Schunk (1992) proposed an additional mode of release called the plasmaspheric wind. This wind was expected to be a slow radial flow pattern, providing a continual loss of plasma from the plasmasphere at all local times. Dandouras (2013) reported the first observation of the plasmaspheric wind, steadily transporting cold plasmaspheric plasma outward across magnetic field lines. The author calculated the plasma transport rate and obtained $\sim 5.10^{26}$ ions s$^{-1}$, which makes it the major source of ionospheric ions escaping
Earth. The spacecraft were separated by 100 and $2000 \mathrm{~km}$ in these events (number 16 in Fig. 2).

Non-thermal continuum (NTC) radiation is a strong source of radio waves localised in the outer boundary of the plasmasphere, the plasmapause. An experiment was conducted with the Cluster spacecraft to improve the accuracy of the localisation of these sources. The experiment involved tilting one of the Cluster spacecraft by $45^{\circ}$ with respect to the other three to measure the electric field of this emission in three dimensions for the first time with long wire booms. Two of the spacecraft were separated by $40 \mathrm{~km}$ and the other two were separated by $10000 \mathrm{~km}$ (number 17 in Fig. 2). Décréau et al. (2013) showed that classical triangulation, in this case using three of the non-tilted spacecraft situated thousands of kilometres apart, can lead to a source location that is nowhere near the boundaries where NTC generation occurs. The erroneous source location, far from these boundaries, given by triangulation is attributed to small deviation from the assumed polarisation of the emission. On the other hand, using the tilted spacecraft and another one close to it, Décréau et al. (2013) showed that the radio waves could be measured in 3-D and its source correctly found on the dawn sector of the plasmapause (Fig. 10).

Lointier et al. (2013) addressed the re-filling of the plasmasphere after an active period. They used Cluster active sounder data (giving absolute electron density between 0.2 and $80 \mathrm{~cm}^{-3}$ ) measured in 2002-2003 (perigee at $4 R_{\mathrm{E}}$ geocentric distance) and in 2007-2009 (perigee at $1.5 R_{\mathrm{E}}$ geocentric distance). They then investigated statistically the evolution of the plasmasphere for three time periods when the activity was quiet for less than 2 days, between 2 and 4 days and above 4 days. The refilling process was clearly shown, with the plasmapause reaching $L=6$ after 3-4 days. Several new plasmasphere properties were found, especially at $L>6$, such as a density knee at mid-latitude and a significant density variation with MLT and refilling duration. At $L=8$, the flux tubes seem not fully filled after 6 days of quiet time.

Using the CODIF ion mass spectrometer instrument, Yamauchi et al. (2014) discovered that $\mathrm{He}+$ could be energised in the inner magnetosphere without observing $\mathrm{H}+$ energisation. This is observed more often after substorm and in the evening sector. Although this is a rather rare observation, since about 20 clear cases have been observed during 6 years of Cluster data, new theory and simulations would be needed to explain this plasmaspheric mass filtering effect.

\subsection{Plasmasphere and radiation belts}

The inner magnetosphere is formed by two different regions: the radiation belts, containing very energetic particles, and the plasmasphere, containing very low energy plasma. These two regions partly overlap and interact with each other through electromagnetic waves. Over the past decade, the four Cluster spacecraft have made numerous studies of these regions, and a recent paper (Darrouzet et al., 2013) has re- 


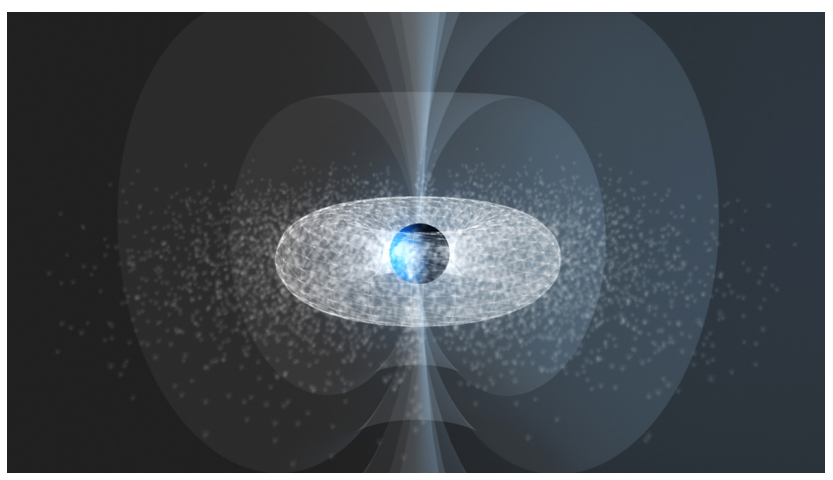

Figure 8. Artist's impression of the plasmasphere, the innermost part of our planet's magnetosphere. The white dots represent the plasmaspheric winds that transfer plasma from the plasmasphere into the magnetosphere at a rate of $\sim 5.10^{26}$ ions s $^{-1}$.
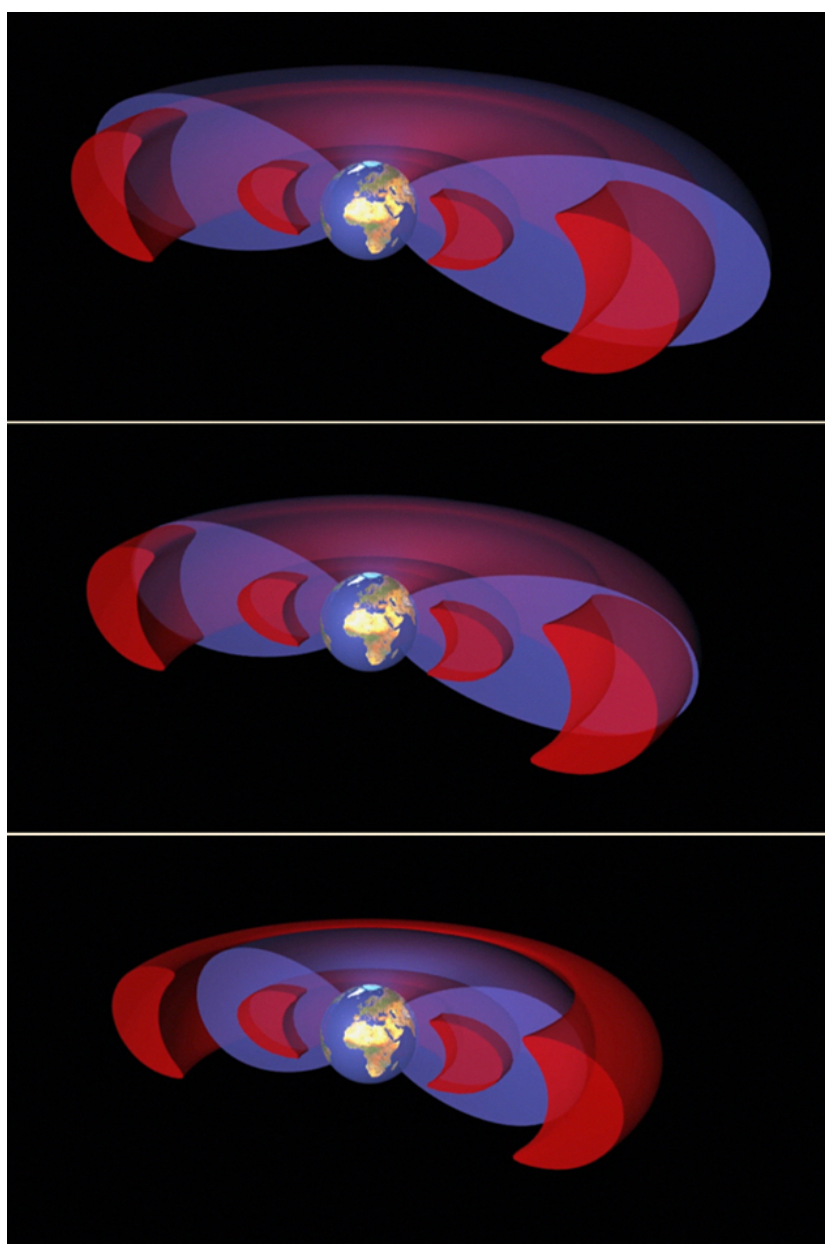

Figure 9. These three panels sketch how the relative locations of the outer boundary of the Earth's plasmasphere, the plasmapause (shown in blue) and the van Allen belts (shown in red) change according to geomagnetic conditions (geomagnetic activity increases from top to bottom). The proton belt is the inner red belt and the electron belt is the outer one.

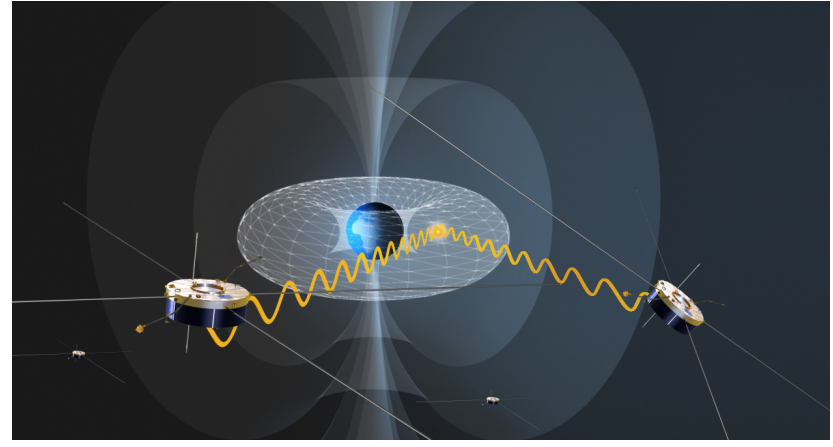

Figure 10. The Cluster tilt campaign. The Cluster spacecraft $\mathrm{C} 3$ and $\mathrm{C} 4$, in the foreground, were used as a single observatory for the study. The C3 spacecraft (right) is shown in the special "tilt" configuration that was used for the observations for a period of 1 month. The $45^{\circ}$ tilt allowed for detection of the signal in 3-D, and showed much better results to the more typical triangulation method.

vealed intriguing links between these overlapping regions. For long periods, when geomagnetic activity was low, the plasmapause was located toward the more distant part of the outer belt, typically around $6 R_{\mathrm{E}}$, but sometimes expanding outward to $8 R_{\mathrm{E}}$ or beyond (Fig. 9). This result was unexpected, since previous studies based on other spacecraft observations indicated a correlation between the position of the inner edge of the outer belt and the position of the plasmapause. However, during the occasional periods of higher geomagnetic activity, the plasmapause moved closer to the inner boundary of the outer radiation belt, at around $4.5 R_{\mathrm{E}}$, as observed by previous studies.

The Cluster mission was not created to study the radiation belts in detail since the instruments are limited in the energy of electrons and ions measured. Ganushkina et al. (2011) used an indirect technique to identify the boundaries of the inner and outer radiation belts. They used the background in low-energy $(<30 \mathrm{keV})$ plasma detectors produced by megaelectron volt particles penetrating through the walls of the instrument. They also used the HIA instrument (an ion detector) on both Cluster and Double Star in 2007-2009 to analyse the variation in radiation belts' boundaries as a function of magnetic activity. The authors showed that the outer radiation belt boundary moved inward from $L=6$ to $L=4$ following an increase of solar wind dynamic pressure. In addition, the slot region, between the inner outer belts, widens during low activity, consistent with weaker inward radial diffusion and weak local acceleration.

Using a conjunction of the Cluster spacecraft and the CANOPUS network, Motoba et al. (2013) demonstrated the direct link between PC5 waves in space and on the ground. Furthermore, oscillations of energetic electrons and chorus waves intensity were observed at Cluster and, simultaneously, an absorption of cosmic ray was seen on the ground, which is a measure of precipitation of electrons in the ionosphere. This is an example where waves precipitate energetic 


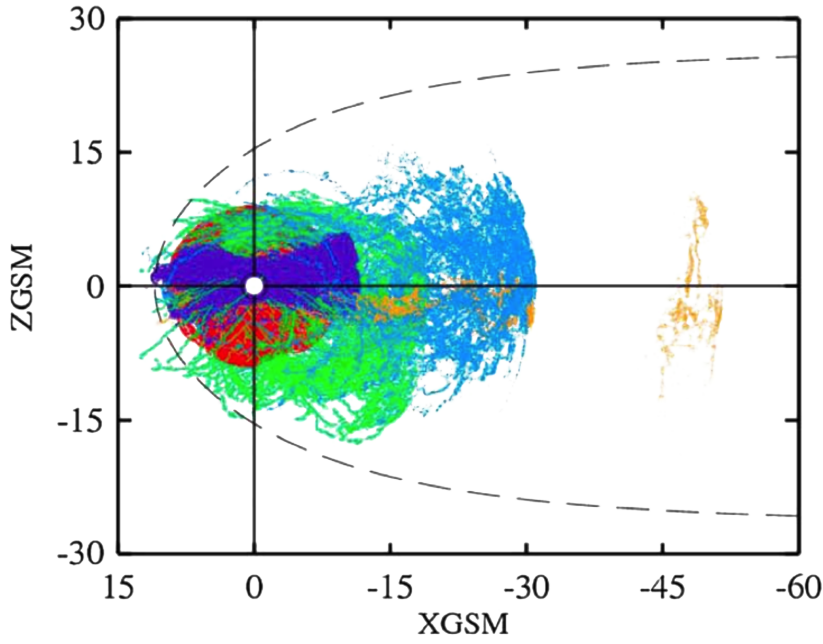

Figure 11. Location of magnetic measurements made by Polar (red), Cluster (green), Geotail (light blue) and THEMIS (dark blue and light brown) to produce the new Tsyganenko model (from Tsyganenko, 2014).

particles into the atmosphere and contribute to the loss of particles in the radiation belts.

\subsection{Magnetosphere at global scales}

Taking advantage of the latest space missions, Tsyganenko (2014) published his new model based on magnetic field measurements made by Cluster, Polar, Geotail and THEMIS during the period 1995-2012. This new model includes important new aspects in the modelling of the magnetosphere such as 123 geomagnetic storms, an IMF-dependent magnetopause model, the deformation of equatorial current sheet with Earth's dipole, a more realistic ring current, and extension on the nightside up to $40-50 R_{\mathrm{E}}$. Cluster played a key role in this new model. Figure 11 displays the spatial distribution of the data used in this modelling, projected on the $X-Z$ plane in GSM coordinates. We can see that Cluster (green) is the only current mission covering the highlatitude external regions of the magnetosphere. Most recent solar-terrestrial missions have been launched in or near the equatorial plane, unlike Cluster, which was launched in a polar orbit and still continues to orbit at high latitudes. Hence, Cluster offers a rare vantage point.

Modelling the electric field globally in the magnetosphere is also important if we want to understand the circulation of plasma between the various regions of the magnetosphere. Matsui et al. (2013) used 6 years of electric field data measured by EDI and EFW instruments to revise its empirical model in the region $2<L<10$. The model was parameterised with the interplanetary electric field and the Kp index. This model has been improved by including more data during high activity. The nightside potential is now more realistic during active periods. The model was compared with previous ones and its advantages were demonstrated.

Using 8 years of Cluster data and about 4000 magnetopause crossings, Anekallu et al. (2013) investigated the energy transfer through the magnetopause. This transfer can be of two types: a load when $\boldsymbol{J} . \boldsymbol{E}>0$ and a generator when $\boldsymbol{J} . \boldsymbol{E}<0$ ( $\boldsymbol{J}$ being the magnetopause current and $\boldsymbol{E}$ the electric field). They showed that for IMF- $\boldsymbol{B}_{z}$ southward, with expected dayside reconnection, the region equatorward of the cusp was a load while the region poleward of the cusp was a generator, as expected in the dayside reconnection model. This was in agreement with the GUMICS MHD model, although some disagreements were observed, probably due to fast motions of the magnetopause.

Lavraud et al. (2013) used 10 years of Cluster data to investigate asymmetries of the magnetosheath flows and changes of the magnetopause shape during low Alfvén Mach number $(M a)$. They showed that during low $M a$ the magnetic forces become dominant and accelerate plasma in the direction perpendicular to the IMF direction in $Y Z_{\mathrm{GSM}}$ plane. Consequently, the magnetopause was shown to be elongated in the IMF direction as predicted by modelling in previous work. Asymmetries in the magnetosphere may be expected in such conditions, and this has been an active topic of research in recent years (see review by Walsh et al., 2014).

\section{Cluster Guest Investigator Programme}

Following the very successful first Guest Investigator (GI) Programme conducted with Cluster in 2011-2013, it was decided to open a new announcement of opportunity in 2014 for observations to be acquired in 2015-2016. The aim of the GI Programme was to open future spacecraft science operations to the community. The announcement of opportunity was open on 17 February 2014 and the GI proposals were received on 4 June 2014. These proposals were first evaluated by the Cluster Science Operations Working Group (SOWG), consisting of Cluster principal investigators, Science Operations team members (Joint Science Operations Centre, JSOC), the Mission Operations Team (European Science Operations Centre, ESOC) and the ESA project science team. Then a peer review committee, consisting of selected members of the SOWG and selected members from the solar system and exploration working group, made the final recommendation. Eight GIs, listed in Table 3, were then selected by the ESA Director of Science and Robotic Exploration in November 2014. The GI investigations are covering the dayside regions, solar wind, bow shock, magnetosheath, the dawn flank of the magnetosphere and the polar cusp as well as the ring current. Currently data have been acquired successfully for the first two GI proposals from O. Alexandrova and D. Burgess. O. Alexandrova's proposal goal is to study turbulence in the solar wind and in particular the dissipation mechanisms at kinetic scales using two spacecraft separated by $6-7 \mathrm{~km}$. D. Burgess's proposal will investigate 
Table 3. List of Cluster guest investigators selected in 2014.

\begin{tabular}{|c|c|c|c|}
\hline Guest investigator & GI proposal title & Laboratory & Implementation period \\
\hline O. Alexandrova & $\begin{array}{l}\text { Study of the dissipation range of solar } \\
\text { wind turbulence }\end{array}$ & Observatory, & February and March 2015 \\
\hline D. Burgess & $\begin{array}{l}\text { Ion pickup coupling in the solar wind } \\
\text { associated with thruster operations }\end{array}$ & QMUL, UK & March 2015 \\
\hline M. Dunlop & $\begin{array}{l}\text { Coordination of Cluster/Swarm for } \\
\text { FACs }\end{array}$ & RAL, UK & June 2015 \\
\hline Y. V. Bogdanova & $\begin{array}{l}\text { Mid-altitude cusp properties, dynamics, } \\
\text { small-scale plasma structure and ion } \\
\text { outflow: simultaneous Cluster measure- } \\
\text { ments at different MLT sectors }\end{array}$ & RAL, UK & $\begin{array}{l}\text { November and December } \\
2015\end{array}$ \\
\hline Y. Khotyaintsev & $\begin{array}{l}\text { Multi-spacecraft Investigation of Elec- } \\
\text { tron Scales at Bow Shock }\end{array}$ & IRF-U, Sweden & January 2016 \\
\hline P. Kajdic & $\begin{array}{l}\text { Magnetic reconnection in the solar } \\
\text { wind: search for small-scale events }\end{array}$ & $\begin{array}{l}\text { ESA/ESTEC, Netherlands } \\
\text { (now at Mexico U.) }\end{array}$ & February 2016 \\
\hline X. Blanco-Cano & $\begin{array}{l}\text { Upstream transients and their influence } \\
\text { on the bow shock and magnetosheath }\end{array}$ & Mexico University, Mexico & April 2016 \\
\hline C. Foullon & $\begin{array}{l}\text { Magnetopause boundary layer: evolu- } \\
\text { tion of plasma and turbulent character- } \\
\text { istics along the flank repeats }\end{array}$ & Exeter University, UK & May-June 2016 \\
\hline
\end{tabular}

the effect of firing the thrusters in the solar wind as it flows over the spacecraft. Such an operation had never been done before because the instruments were turned off or were in a standby state during manoeuvres. In this GI observation the electric and magnetic field instruments and the wave instruments were switched on during a 20 min long thruster firing.

\section{Open and easy access to high-resolution Cluster data}

After the Cluster launch, the data were distributed to the community through the Cluster Science Data System (CSDS) (Schmidt et al., 1997). The prime parameter data (4 s resolution from four spacecraft) were restricted to the PIs and CoIs (co-investigators) and the summary parameters (1 min from Cluster 3) were publicly available. It was realised a few years after launch that detailed analysis of data from the four spacecraft required easy and broad access to the highest spatial and temporal resolution data that are well calibrated. These include such measurements as ion and electron distribution functions, electromagnetic waves waveforms and highest resolution of electric field (36000 samples $\mathrm{s}^{-1}$ ) and magnetic field (4000 samples s ${ }^{-1}$ ). In early 2003, the Cluster Active Archive (CAA), a public archive containing all highresolution calibrated Cluster data, was presented to and approved by the ESA SPC as one of ESA's contributions to the International Living With a Star (ILWS) programme. Additional funding was provided to build the central archive system and to improve the instrument calibrations and to deliver data and metadata. A simple tabular format, the Cluster Exchange Format (CEF), was chosen for data storage. All data can also be retrieved in Common Data Format (CDF) for wide compatibility.
The CAA opened to the public in February 2006 (Laakso et al., 2010). The science community using CAA data has been growing continuously since 2006 at a rate around 20 new users every month, and now more than 1800 scientists are using the data. The download rate has also been continuously growing, and at the beginning of 2015 it was on average above $4 \mathrm{~TB}$ month $^{-1}$. Furthermore, a large portion of Cluster published papers (Table 2) are using data from CAA and their number has clearly increased since 2006, the year of CAA opening. Since November 2014, the Cluster Science Archive (CSA) has superseded the CAA as the public interface to the Cluster mission archive. The CAA remains active, being responsible for the production of calibrated data sets. The CSA design is based on the CAA interface, so the look and feel are meant to be familiar to users of its predecessor. The CSA services can be accessed either via its Java-based graphical user interface (Fig. 12) or by using its archive interoperability interface (command line, data streaming). Recently, the ESA-China mission Double Star data were added to the archive as well as MAARBLE and ECLAT European FP7 project data.

\section{Summary and conclusion}

After 14 years in space, the Cluster mission continues to make breakthroughs in space science due to its continuous ability to change the spacecraft configuration, the evolution of its orbit, and the substantial amount of high-resolution data returned. The recent highlights presented here have shed new light on solar wind turbulence. They demonstrated that the magnetosheath can be asymmetric under low Mach number and can contain density enhancement that may affect the 


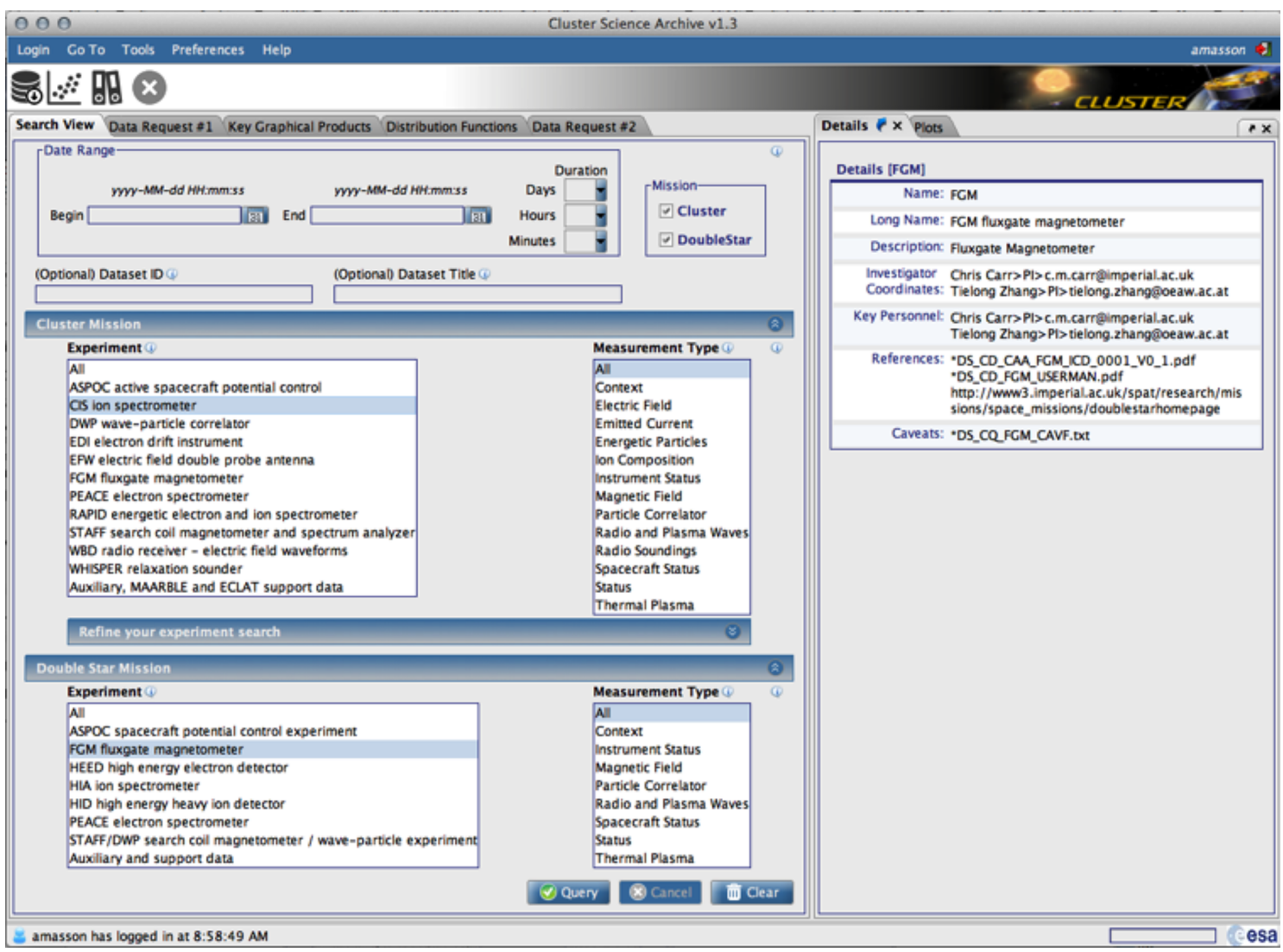

Figure 12. Cluster Science Archive Java interface.

magnetosphere. The magnetopause was found to be thinner and to have a higher density current on the duskside than the dawnside, together with an asymmetry in the ring current. New methods have been used to obtain magnetotail current sheet characteristics and high-temporal-resolution measurements of electron pitch angle within FTEs. New models of the global electric and magnetic field of the magnetosphere have been obtained where Cluster data, due to the polar orbit, have been essential. Plasmaspheric wind has been discovered and the refilling of the plasmasphere could be observed for the first time over a very wide range of $L$ shells. Finally, magnetic reconnection could be viewed for the first time with high-resolution waves and electron measurements and acceleration of plasma was observed when the magnetic reconnection rate was varying.

The Cluster orbit has changed significantly in the last 5 years, with a perigee moving from $4 R_{\mathrm{E}}$ to a few hundreds of kilometres and an apogee moving to the Southern Hemisphere. The perigee has been raising again for a few years now, and the apogee is moving back northward. New regions will be visited in the future such as the near-Earth region around 6-7 $R_{\mathrm{E}}$ and the polar cusp, which will be crossed in the azimuthal direction. Multi-mission collaborations with Van Allen Probes, THEMIS and Geotail as well as the re- cently launched Swarm and MMS missions will also significantly enhance the scientific return.

Cluster, together with the MMS mission, will allow, for the first time, a study of magnetic reconnection at small and large scales simultaneously using four-point measurements in the same region of the magnetosphere. Strong collaboration will also continue with ground-based observatories such as SuperDARN and the future EISCAT 3-D, since they will give the context of where spacecraft data need to be put in perspective. The Cluster mission has now been extended up to the end of 2016 and a preliminary extension has been approved for an extra 2 years.

Acknowledgements. The authors thank the PI teams for keeping instruments in very good shape after more than 14 years in space: K. Torkar (IWF, Austria), I. Dandouras (IRAP/CNRS, France), R. Torbert (UNH, USA), C. Carr (IC, UK), A. Fazakerley (MSSL, UK), P. Daly (MPS, Germany), M. Balikhin (Sheffield, UK), M. André (IRFU, Sweden), P. Canu (LPP, France), J. Pickett (U. Iowa, USA) and J.-L. Rauch (LPC2E, France). We thank K. Yearby and O. Santolík and their teams for their help to continue operating the WBD instrument and deliver data. We thank M. Taylor, who was a Cluster project scientist until recently and contributed greatly to the success of Cluster. We also thank the ESOC and JSOC teams for spacecraft and science operations as well as Airbus Defence and Space (Ger- 
many) for their continuous spacecraft operation support. We would like to thank the CAA and CSA archiving teams and the CSDS teams at national data centres.

Cluster data can be accessed at http://cosmos.esa.int/csa. More information on the Cluster mission, including its publications and PhD studies, are available at http://sci.esa.int/cluster/.

During the revision of this paper we learned the terrible news that Alain Roux had passed away on 27 July 2015. Alain was one of the founding fathers of Cluster and supported it continuously with great enthusiasm over more than three decades. He will be greatly missed by the Cluster community.

The topical editor G. Balasis thanks two anonymous referees for help in evaluating this paper.

\section{References}

Alexandrova, O., Lacombe, C., Mangeney, A., Grappin, R., and Maksimovic, M.: Solar wind turbulence spectrum at plasma kinetic scales, Astrophys. J., 760, 121, 2012.

Anekallu, C. R., Palmroth, M., Koskinen, H. E. J., Lucek, E., and Dandouras, I.: Spatial variation of energy conversion at the Earth's magnetopause: Statistics from Cluster observations, J. Geophys. Res.-Space, 118, 1948-1959, doi:10.1002/jgra.50233, 2013.

Brenning, N., Hurtig, T., and Raadu, M.: Conditions for plasmoid penetration across abrupt magnetic barriers, Phys. Plasmas, 12, 1-10, doi:10.1063/1.1812277, 2005.

Cao, J., Ma, Y., Parks, G., Rème, H., Dandouras, I., and Zhang, T.: Kinetic analysis of the energy transport of bursty bulk flows in the plasma sheet, J. Geophys. Res.-Space, 118, 313-320, doi:10.1029/2012JA018351, 2013.

Credland, J. and Schmidt, R.: The Resurrection of the Cluster Scientific Mission, ESA Bulletin No. 91, 1997.

Dandouras, I.: Detection of a plasmaspheric wind in the Earth's magnetosphere by the Cluster spacecraft, Ann. Geophys., 31, 1143-1153, doi:10.5194/angeo-31-1143-2013, 2013.

Darrouzet, F., De Keyser, J., and Pierrard, V.: The Earth's Plasmasphere - A Cluster and Image Perspective, Space Sci. Rev., 145, 1-2, 2009.

Darrouzet, F., Pierrard, V., Benck, S., Lointier, G., Cabrera, J., Borremans, K., Ganushkina, N. Y., and De Keyser, J.: Links between the plasmapause and the radiation belt boundaries as observed by the instruments CIS, RAPID and WHISPER onboard Cluster, J. Geophys. Res.-Space, 118, 4176-4188, doi:10.1002/jgra.50239, 2013.

Décréau, P. M. E., Kougblénou, S., Lointier, G., Rauch, J.-L., Trotignon, J.-G., Vallières, X., Canu, P., Rochel-Grimald, S., ElLemdani Mazouz, F., and Darrouzet, F.: Remote sensing of a NTC radio source from a Cluster tilted spacecraft pair, Ann. Geophys., 31, 2097-2121, doi:10.5194/angeo-31-2097-2013, 2013.

Escoubet, C. P., Fehringer, M., and Goldstein, M.: Introduction The Cluster mission, Ann. Geophys., 19, 1197-1200, doi:10.5194/angeo-19-1197-2001, 2001.

Escoubet, C. P., Taylor, M. G. G. T., Masson, A., Laakso, H., Volpp, J., Hapgood, M., and Goldstein, M. L.: Dynamical processes in space: Cluster results, Ann. Geophys., 31, 1045-1059, doi:10.5194/angeo-31-1045-2013, 2013a.

Escoubet, C. P., Berchem, J., Trattner, K. J., Pitout, F., Richard, R., Taylor, M. G. G. T., Soucek, J., Grison, B., Laakso, H.,
Masson, A., Dunlop, M., Dandouras, I., Reme, H., Fazakerley, A., and Daly, P.: Double cusp encounter by Cluster: double cusp or motion of the cusp?, Ann. Geophys., 31, 713-723, doi:10.5194/angeo-31-713-2013, 2013 b.

Fu, H. S., Khotyaintsev, Y. V., Vaivads, A., Retinò, A., and André, M.: Energetic electron acceleration by unsteady magnetic reconnection, Nature Phys., 9, 426-430, doi:10.1038/nphys2664, 2013.

Fuselier, S. A., Petrinec, S. M., Trattner, K. J., and Lavraud, B.: Magnetic field topology for northward IMF reconnection: Ion observations, J. Geophys. Res., 119, 9051-9071, doi:10.1002/2014JA020351, 2014.

Ganushkina, N. Y., Dandouras, I., Shprits, Y. Y., and Cao, J.: Locations of boundaries of outer and inner radiation belts as observed by Cluster and Double Star, J. Geophys. Res., 116, A09234, doi:10.1029/2010JA016376, 2011.

Gunell, H., Nilsson, H., Stenberg, G., Hamrin, M., Karlsson, T., Maggiolo, R., André, M., Lundin, R., and Dandouras, I.: Plasma penetration of the dayside magnetopause, Phys. Plasmas, 19, 072906, doi:10.1063/1.4739446, 2012.

Haaland, S. and Gjerloev, J.: On the relation between asymmetries in the ring current and magnetopause current, J. Geophys. Res.Space, 118, 7593-7604, doi:10.1002/2013JA019345, 2013.

Haerendel, G., Roux, A., Blanc, M., Paschmann, G., Bryant, D., Korth, A., and Hultqvist, B.: Cluster, study in three dimensions of plasma turbulence and small-scale structure, mission proposal submitted to ESA, 1982.

Karlsson, T., Brenning, N., Nilsson, H., Trotignon, J.-G., Vallières, X., and Facsko, G.: Localized density enhancements in the magnetosheath: Three-dimensional morphology and possible importance for impulsive penetration, J. Geophys. Res., 117, A03227, doi:10.1029/2011JA017059, 2012.

Kronberg E. A., Haaland, S. E., Daly, P. W., Grigorenko, E. E., Kistler, L. M., Fränz, M., and Dandouras, I.: Oxygen and hydrogen ion abundance in the near-Earth magnetosphere: Statistical results on the response to the geomagnetic and solar wind activity conditions, J. Geophys. Res., 117, A12208, doi:10.1029/2012JA018071, 2012.

Laakso, H., Perry, C., McCaffrey, S., Herment, D., Allen, A. J., Harvey, C. C., Escoubet, C. P., Gruenberger, C., Taylor, M. G. G. T., and Turner, R.: Cluster Active Archive: Overview, The Cluster Active Archive, in: Astrophysics and Space Science Proceedings, edited by: Laakso, H., Springer, the Netherlands, 3-37, doi:10.1007/978-90-481-3499-1_1, 2010.

Lavraud, B., Larroque, E., Budnik, E., Génot, V., Borovsky, J. E., Dunlop, M. W., Foullon, C., Hasegawa, H., Jacquey, C., Nykyri, K., Ruffenach, A., Taylor, M. G. G. T., Dandouras, I., and Rème, H.: Asymmetry of magnetosheath flows and magnetopause shape during low Alfvén Mach number solar wind, J. Geophys. Res., 118, 1089-1100, doi:10.1002/jgra.50145, 2013.

Lemaire, J. F. and Schunk, R. W.: Plasmaspheric wind, J. Atmos. Terr. Phys., 54, 467-477, 1992.

Lointier, G., Darrouzet, F., Décréau, P. M. E., Vallières, X., Kougblénou, S., Trotignon, J. G., and Rauch, J.-L.: Refilling process in the plasmasphere: a 3-D statistical characterization based on Cluster density observations, Ann. Geophys., 31, 217-237, doi:10.5194/angeo-31-217-2013, 2013.

Matsui, H., Torbert, R. B., Spence, H. E., Khotyaintsev, Y. V., and Lindqvist, P.-A.: Revision of empirical electric field modeling in 
the 1 inner magnetosphere using Cluster data, J. Geophys. Res. Space Phys., 118, 4119-4134, doi:10.1002/jgra.50373, 2013.

Motoba, T., Takahashi, K., Gjerloev, J., Ohtani, S., and Milling, D. K.: The role of compressional Pc5 pulsations in modulating precipitation of energetic electrons, J. Geophys. Res.-Space, 118, 7728-7739, doi:10.1002/2013JA018912, 2013.

Narita, Y.: Four-dimensional energy spectrum for space-time structure of plasma turbulence, Nonlin. Processes Geophys., 21, 4147, doi:10.5194/npg-21-41-2014, 2014.

Narita, Y., Nakamura, R., and Baumjohann, W.: Cluster as current sheet surveyor in the magnetotail, Ann. Geophys., 31, 16051610, doi:10.5194/angeo-31-1605-2013, 2013.

Norgren, C., Vaivads, A., Khotyaintsev, Y. V., and André, M.: Lower hybrid drift waves: space observations, Phys. Rev. Lett., 109, 055001, doi:10.1103/PhysRevLett.109.055001, 2012.

Paschmann G., Escoubet, C. P., Schwartz, S. J., and Haaland, S. E.: Outer magnetospheric boundaries: Cluster results, 118/1-4, ISBN 1-4020-3488-1, Springer, Berlin, Germany, 2005.

Perri, S., Goldstein, M. L., Dorelli, J. C., and Sahraoui, F.: Detection of Small-Scale Structures in the Dissipation Regime of Solar-Wind Turbulence, Phys. Rev. Lett., 109, 191101, doi:10.1103/PhysRevLett.109.191101, 2012.

Roux, A., Robert, P., Fontaine, D., Le Contel, O., Canu, P., and Louarn, P.: What is the nature of magnetosheath FTEs?, J. Geophys. Res.-Space, 120, 4576-4595, doi:10.1002/2015JA020983, 2015.

Sahraoui, F., Belmont, G., and Goldstein, M. L.: New insight into short wavelength solar wind fluctuations from Vlasov theory, Astrophys. J., 748, 11 pp., doi:10.1088/0004-637X/748/2/100, 2012.

Schmidt, R., Escoubet, C. P., and Schwartz, S.: The Cluster Science Data System (CSDS) - A new approach to the distribution of scientific data, Space Sci. Rev., 79, 557-582, 1997.

Servidio, S., Gurgiolo, C., Carbone V., and Goldstein, M. L.: Relaxation Processes in Solar Wind Turbulence, Astrophys. J., 789, L44, 5 pp., 2014.
Shi, J., Zhang, Z., Torkar, K., Dunlop, M., Fazakerley, A., Cheng, Z., and Liu, Z.: Temporal and spatial scales of a high-flux electron disturbance in the cusp region: Cluster observations, J. Geophys. Res.-Space, 119, 4536-4543, doi:10.1002/2013JA019560, 2014.

Tsyganenko, N. A.: Data-based modeling of the geomagnetosphere with an IMF-dependent magnetopause, J. Geophys. Res.-Space, 119, 335-354, doi:10.1002/2013JA019346, 2014.

Varsani, A., Owen, C. J., Fazakerley, A. N., Forsyth, C., Walsh, A. P., André, M., Dandouras, I., and Carr, C. M.: Cluster observations of the substructure of a flux transfer event: analysis of high-time-resolution particle data, Ann. Geophys., 32, 1093 1117, doi:10.5194/angeo-32-1093-2014, 2014.

Viberg, H., Khotyaintsev, Y. V., Vaivads, A., André, M., and Pickett, J. S.: Mapping HF waves in the reconnection diffusion region, Geophys. Res. Lett., 40, 1032-1037, doi:10.1002/grl.50227, 2013.

Walsh, B. M., Sibeck, D. G., Wang, Y., and Fairfield, D. H.: Dawndusk asymmetries in the Earth's magnetosheath, J. Geophys. Res., 117, A12211, doi:10.1029/2012JA018240, 2012.

Walsh, A. P., Haaland, S., Forsyth, C., Keesee, A. M., Kissinger, J., Li, K., Runov, A., Soucek, J., Walsh, B. M., Wing, S., and Taylor, M. G. G. T.: Dawn-dusk asymmetries in the coupled solar windmagnetosphere-ionosphere system: a review, Ann. Geophys., 32, 705-737, doi:10.5194/angeo-32-705-2014, 2014.

Yamauchi, M., Dandouras, I., Rèeme, H., and Nilsson, H.: Cluster observations of hot $\mathrm{He}+$ events in the inner magnetosphere, J. Geophys. Res., 119, 2706-2716, doi:10.1002/2013JA019724, 2014.

Yao, Z., Sun, W. J., Fu, S. Y., Pu, Z. Y., Liu, J., Angelopoulos, V., Zhang, X.-J.; Chu, X. N., Shi, Q. Q., Guo, R. L., and Zong, Q.-G.: Current structures associated with dipolarization fronts, J. Geophys. Res., 118, 6980-6985, doi:10.1002/2013JA019290, 2013. 